\title{
Photoinduced Processes in a Tricomponent Molecule Consisting of Diphenylaminofluorene-Dicyanoethylene-Methano[60]fullerene
}

\author{
Mohamed E. El-Khouly, ${ }^{\text {a,b }}$ Prashant Padmawar, ${ }^{\mathrm{c}}$ Yasuyuki Araki, ${ }^{\mathrm{a}}$ Sarika Verma, \\ Long Y. Chiang, ${ }^{\mathrm{c}} *$ and Osamu Ito ${ }^{\mathrm{a}, *}$
}

Institute of Multidisciplinary Research for Advanced Materials, Tohoku University, Katahira, Aoba-ku, Sendai 980-8577, Japan, Department of Chemistry, Faculty of Education, Tanta University, Kafr El-Sheikh, Egypt, Center for Condensed Matter Sciences, National Taiwan University, Taipei, Taiwan, and Department of Chemistry, Institute of Nanoscience and Engineering, University of Massachusetts Lowell, 1 University Avenue, Lowell, MA 01854-5047, USA

\footnotetext{
${ }^{a}$ Tohoku University

${ }^{\mathrm{b}}$ Tanta University

${ }^{\mathrm{c}}$ University of Massachusetts Lowell

(Abstract)
} 


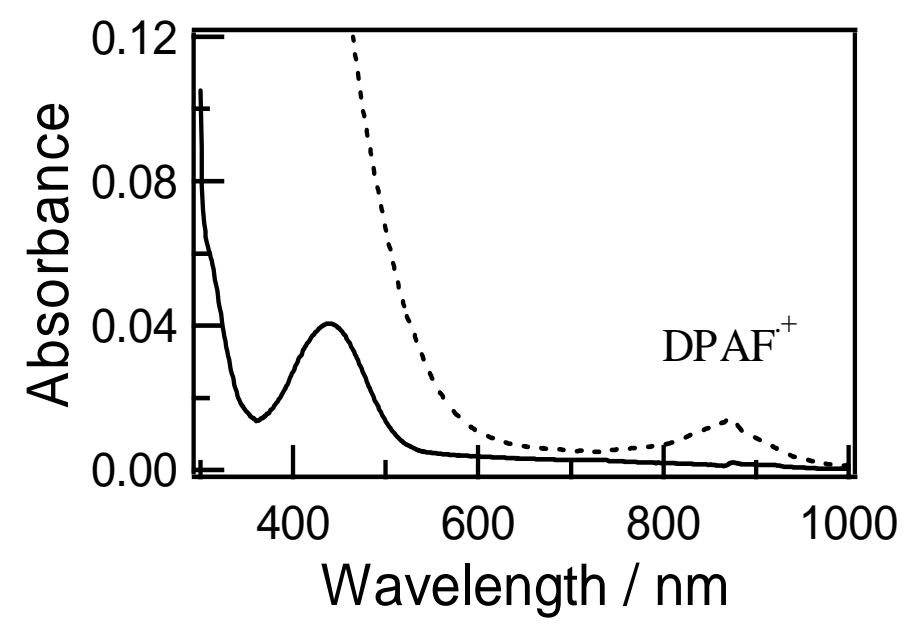

Figure S1. Absorbance of $(\mathrm{CN})_{2}-\operatorname{DPAF}\left(5 \times 10^{-3} \mathrm{mM}\right)$ in the presence and absence of $\mathrm{FeCl}_{3}(0.1 \mathrm{M})$ in DCB.

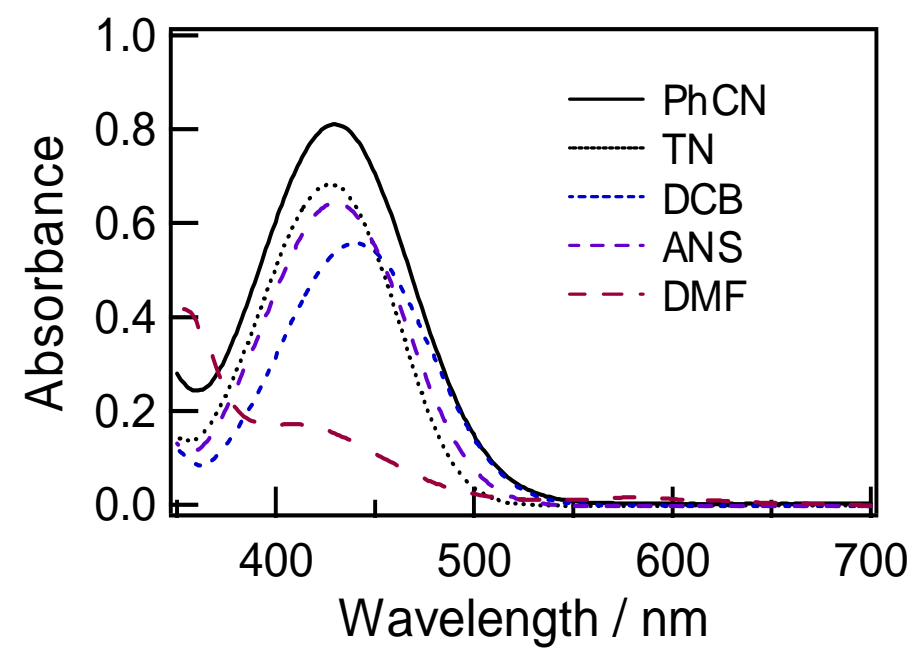

Figure S2. Steady-state absorption spectra of $(\mathrm{CN})_{2}-\mathrm{DPAF}$ in different solvents. The concentrations were maintained at $5 \times 10^{-3} \mathrm{mM}$. 


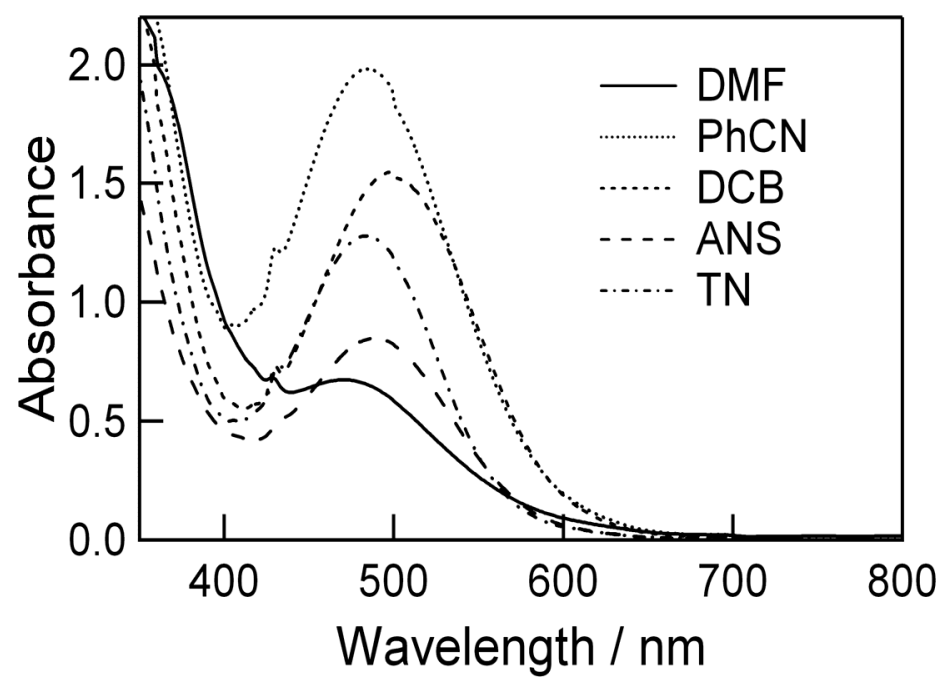

Figure S3. Steady-state absorption spectra of $\mathrm{C}_{60}\left(>(\mathrm{CN})_{2}-\mathrm{DPAF}\right)$ in different solvents. The concentrations were maintained at $5 \times 10^{-3} \mathrm{mM}$.

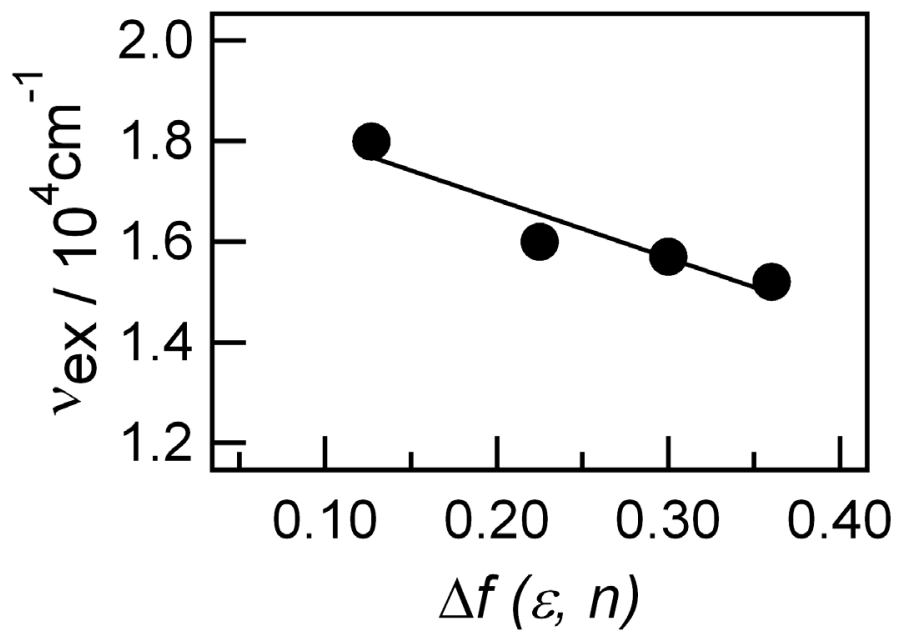

Figure S4. Relation between $v_{\mathrm{ex}}$ and $\Delta \mathrm{f}(\varepsilon, \mathrm{n})$ for $(\mathrm{CN})_{2}-\mathrm{DPAF}$ in different solvents. 


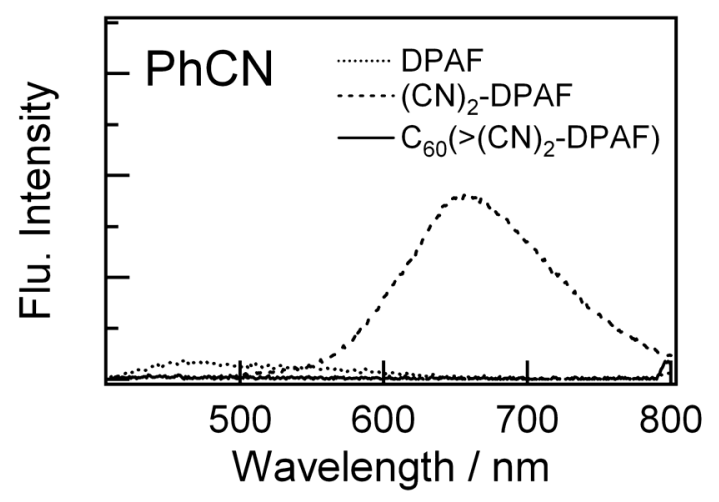

Figure S5. Steady-state fluorescence spectra of DPAF, $(\mathrm{CN})_{2}-\mathrm{DPAF}$ and $\mathrm{C}_{60}\left(>(\mathrm{CN})_{2}-\mathrm{DPAF}\right)$ in $\mathrm{PhCN}$.

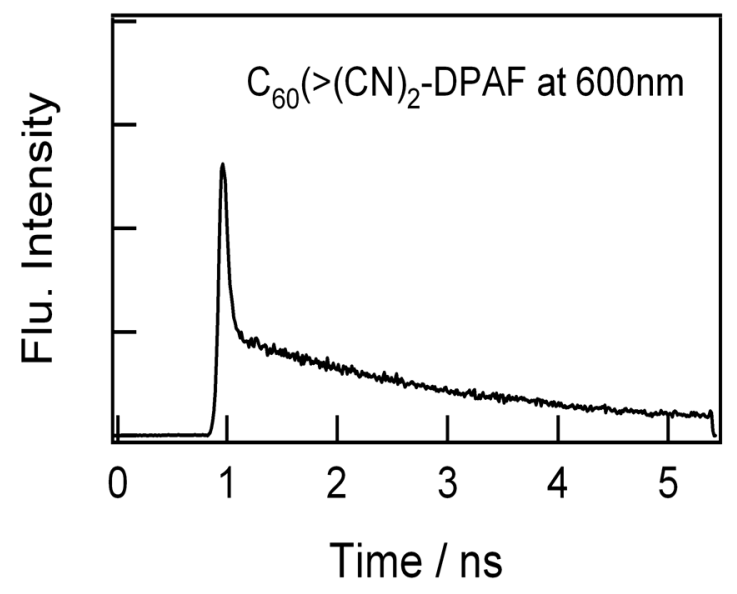

Figure S6. Fluorescence decay profiles of $\mathrm{C}_{60}\left(>(\mathrm{CN})_{2}-\mathrm{DPAF}\right)$ monitored at $600 \mathrm{~nm}$ in $\mathrm{PhCN}$. The concentrations were maintained at $0.05 \mathrm{mM} ; \lambda_{\mathrm{ex}}=400 \mathrm{~nm}$. 